\title{
Emergency general surgery in Italy during the COVID-19 outbreak: first survey from the real life
}

\author{
Alberto Patriti ${ }^{*}$, Gian Luca Baiocchi ${ }^{2}$, Fausto Catena ${ }^{3}$, Pierluigi Marini ${ }^{4}$, Marco Catarci ${ }^{5}$ and FACS on behalf of the \\ Associazione Chirurghi Ospedalieri Italiani (ACOI)
}

\begin{abstract}
Background: COVID-19 pandemic has rapidly spread in Italy in late February 2020. Almost all surgical services have been reorganized, with the aim of maintaining an adequate therapeutic path, especially for surgical emergencies. The knowledge of how surgeons dealing with emergency surgery have reacted to the epidemic in the real life can be useful while drafting clinical recommendations.

Methods: Surgeons from multiple Italian regions were invited answering to an online survey in order to make a snapshot of their current behaviors towards COVID-19-positive patients bearing urgent surgical diseases. Questions about institutional rules and personal approach for patient treatment and to limit epidemic spread were included in a 37-item questionnaire.

Results: Seventy-one questionnaires from institutions dealing with emergency surgery were accepted. Participating surgeons were equally subdivided from a geographical point of view, with a large proportion of public (97.2\%) and non-academical (91.5\%) centers. In 80.3\% of cases, the hospitals treated COVID-19 patients; in $69.1 \%$ of centers, a change in work plan was necessary, and $33.8 \%$ of teams had almost a surgeon infected or in preventive quarantine. The vast majority of surgeons operated only on urgent cases (73.9\%), but the number of interventions significantly dropped. Up to $40 \%$ of non-traumatic abdominal emergency cases had an unusual delayed treatment. The laparoscopic approach was used in 69.6\% of interventions on COVID-19 patients. Strategies to protect health care workers against COVID-19 infection and to identify asymptomatic infected surgeons were suboptimal with respect to the $\mathrm{WHO}$ recommendations in $70.4 \%$ and $90.2 \%$ of centers, respectively. Advanced personal protective equipment for operating room workers was adopted for all surgeries in only $12.7 \%$ of centers.

(Continued on next page)
\end{abstract}

\footnotetext{
* Correspondence: alberto.patriti@ospedalimarchenord.it

The members of ACOI are co-authors of this article and may be found under the heading contributors

${ }^{1}$ Department of Surgery, Azienda Ospedaliera Marche Nord, Ospedale San Salvatore, Piazzale Cinelli 1, Pesaro-Fano, Italy

Full list of author information is available at the end of the article
}

(c) The Author(s). 2020 Open Access This article is licensed under a Creative Commons Attribution 4.0 International License, which permits use, sharing, adaptation, distribution and reproduction in any medium or format, as long as you give appropriate credit to the original author(s) and the source, provide a link to the Creative Commons licence, and indicate if changes were made. The images or other third party material in this article are included in the article's Creative Commons licence, unless indicated otherwise in a credit line to the material. If material is not included in the article's Creative Commons licence and your intended use is not permitted by statutory regulation or exceeds the permitted use, you will need to obtain permission directly from the copyright holder. To view a copy of this licence, visit http://creativecommons.org/licenses/by/4.0/ The Creative Commons Public Domain Dedication waiver (http://creativecommons.org/publicdomain/zero/1.0/) applies to the data made available in this article, unless otherwise stated in a credit line to the data. 
(Continued from previous page)

Discussion: This survey confirms that the COVID-19 outbreak is dramatically changing the practice of emergency surgery centers in Italy. Despite the reduction in number, urgent cases were on average more challenging owing to diagnostic delay. Recommendations from the International Scientific Societies are frequently not complied concerning the use of laparoscopic approach, the availability of personal protective equipment in the operating rooms, and the testing of both asymptomatic physicians and patients scheduled for surgery. A further evaluation of the short-term results of these attitudes is warranted to modulate international recommendations.

Keywords: Coronavirus, COVID-19, Epidemic, Pandemic, Emergency surgery, Laparoscopy, Management, Resources, Surgery

\section{Introduction}

The COVID-19 epidemic was declared by the World Health Organization (WHO) as a public health emergency on January 30, 2020 [1]. After an initial diffusion in China [2], Italy represents one of the most affected countries, with more than 110,000 cases on April 1, 2020 [3]. Worldwide health systems were reorganized with the aim to both cope with the new disease and maintain essential health service delivery. In this scenario, a concrete risk of health system collapse should be taken into consideration. The large number of patients suffering from respiratory distress syndrome led to an inevitable modification of daily clinical and surgical activity. Various international surgical societies constantly update their recommendations in order to adapt surgical activity on current conditions [4-8]. Italian investigators have already published their experience and the consequent suggestions for general surgery $[9,10]$. Unanimously, the goal is to provide timely surgical care to patients presenting with urgent and emergent conditions while optimizing patient care resources and preserving the health of caregivers. However, the current impact of the COVID-19 outbreak on emergency surgery practice is still not investigated. The Associazione Chirurghi Ospedalieri Italiani (Italian Association of Hospital Surgeons, ACOI) is the larger surgical society in Italy, collecting more than 2800 general surgeons from all over the country. It represents, therefore, an ideal background for a survey aimed to show a snapshot of the current practice of emergency surgery in Italy, and our country represents a model of great interest for many countries with similar social-health organization.

\section{Methods}

A 37-item questionnaire was sent to 150 Italian chiefs of General Surgery Units within the ACOI network. A small number of academic surgical units with interest in emergency surgery were also invited. The questionnaire was structured in 4 sections: [1] hospital trait, size, and mission; surgical unit, operating rooms, and intensive care unit (ICU) hallmark; and resources dedicated to COVID-19 patients [2]. Surgical team changes in human resources, duty, and work plan; surgeon infection and quarantine; and responsibility for strategic decisions [3]. Emergency interventions in COVID-19 patients, as per number, indications, surgical presentation, surgical approach, and post-operative complications [4]. Supply of personal protective equipment (PPE), asymptomatic surgeons and/or surgical patient investigation for COVID19 infection, strategy for limiting the spread of epidemic into the hospital, and intraoperative measures for operating room workers protection. A 48-h time was given for filling the questionnaire. All quantitative values were expressed as mean \pm standard deviation (SD), 95\% confidence intervals $(95 \% \mathrm{CI})$, and median and categorical data with percentage frequencies. Differences in continuous data were analyzed using non-parametric tests (Mann-Whitney $U$ or Kruskal-Wallis tests as indicated).

\section{Results}

Eighty-two questionnaires were returned and reviewed. Nine centers were excluded because of not performing emergency surgery, and 2 questionnaires resulted incomplete. Therefore, answers from 71 Italian general surgery units practicing emergency surgery [11] were analyzed (compliance 47.3\%): 35 from the northern regions and 36 from the central-southern regions. All but 2 questionnaires came from public hospitals (Table 1). In $80.3 \%$ of cases, the hospital was accepting COVID-19positive patients, and $9.8 \%$ of them were exclusively dedicated to COVID-19 cases.

The overall number of staff surgeons remained unchanged in $76.1 \%$ of hospitals, but in $46.5 \%$ of surgical departments, one or more surgeons were moved to the Internal Medicine or Emergency Department (ED). Shifts in the work plan were planned in $69.1 \%$ of centers in order to minimize the risk of infection. At least one surgeon resulted to be tested positive for COVID-19 in $28.2 \%$ of the centers, and in $33.8 \%$, at least one team member was quarantined (Table 2).

In 23 out of 57 hospitals admitting COVID-19 patients, surgery was carried out in COVID-19 patients (40.3\%). The vast majority of surgeons operated only on urgent cases $(73.9 \%)$, while $21.7 \%$ continued to perform 
Table 1 Surgeons and institutions participating in the survey

\begin{tabular}{|c|c|c|c|}
\hline & & Number & Percent \\
\hline \multirow[t]{3}{*}{ Type of hospital } & Public, academic & 7 & 9.8 \\
\hline & Public, non-academic & 62 & 87.3 \\
\hline & Private & 2 & 2.8 \\
\hline \multirow[t]{2}{*}{ Region } & Northern Italy & 35 & 49.3 \\
\hline & South-Central Italy & 36 & 50.7 \\
\hline \multirow[t]{4}{*}{ Total bed number } & $<201$ & 21 & 29.6 \\
\hline & $201-500$ & 28 & 39.4 \\
\hline & $501-1000$ & 17 & 23.9 \\
\hline & $>1000$ & 5 & 7.1 \\
\hline \multirow[t]{4}{*}{ ICU beds } & $<10$ & 39 & 54.9 \\
\hline & $10-30$ & 24 & 33.8 \\
\hline & $31-50$ & 6 & 8.4 \\
\hline & $>50$ & 2 & 2.8 \\
\hline \multirow[t]{3}{*}{ COVID cases } & No & 17 & 23.9 \\
\hline & Yes, COVID and no-COVID cases & 47 & 66.2 \\
\hline & Yes, only COVID cases & 7 & 9.8 \\
\hline \multirow[t]{4}{*}{ Estimated COVID cases on March 29, 2020} & $<10$ & 15 & 21.1 \\
\hline & $11-30$ & 10 & 14.1 \\
\hline & $31-60$ & 15 & 21.1 \\
\hline & $>60$ & 31 & 43.7 \\
\hline \multirow[t]{4}{*}{ Estimated ICU COVID cases on March 29, 2020} & $<10$ & 31 & 43.7 \\
\hline & $11-30$ & 33 & 46.5 \\
\hline & $31-50$ & 3 & 4.2 \\
\hline & $>50$ & 4 & 5.6 \\
\hline
\end{tabular}

Table 2 Influence of the COVID-19 epidemic on the surgical team

\begin{tabular}{|c|c|c|c|}
\hline & & Number & Percent \\
\hline \multirow[t]{3}{*}{ Strategy facing the emergency } & Shared with hospital management & 34 & 47.8 \\
\hline & Independently settled by dept. chair & 6 & 8.4 \\
\hline & Imposed by the hospital management & 31 & 43.6 \\
\hline \multirow[t]{3}{*}{ Number of surgeons } & Increased & 1 & 1.4 \\
\hline & Reduced & 16 & 22.5 \\
\hline & Unchanged & 54 & 76.1 \\
\hline \multirow[t]{2}{*}{ Surgeons allocated to other departments } & Yes & 33 & 46.5 \\
\hline & No & 38 & 53.5 \\
\hline \multirow[t]{2}{*}{ Change in the work plan (forced vacations) } & Yes & 49 & 69.0 \\
\hline & No & 22 & 30.9 \\
\hline \multirow[t]{2}{*}{ Team surgeon infected by SARS-Cov2 } & Yes & 20 & 28.2 \\
\hline & No & 51 & 71.9 \\
\hline \multirow[t]{2}{*}{ Team surgeon on quarantine } & Yes & 24 & 33.8 \\
\hline & No & 47 & 66.2 \\
\hline
\end{tabular}


Table 3 Number of urgent surgical procedures performed in participating surgical centers

\begin{tabular}{lllllll}
\hline Period & Overall number. & Mean \pm SD & Median & $95 \% \mid C$ & Range & $p^{*}$ \\
\hline March 2019 & 2090 & $29.8 \pm 22.3$ & 23 & $24.5-35.2$ & $1-94$ & $1-102$ \\
$2020(1)$ & 2190 & $31.7 \pm 15.7$ & 24 & $22.3-41.2$ & 0.0001 \\
$2020(2)$ & 1086 & $15.7 \pm 14.9$ & 10 & $12.1-19.3$ & $0-80$ & \\
\hline
\end{tabular}

SD standard deviation; 95\%IC 95\% interval confidence; 2020 [1] January 23 to February 22, 2020; 2020 [2] February 23 to March 22, 2020

${ }^{*}$ March 2019-2020 [1], $p=0.826 ; 2020$ [1]-2020 [2], $p<0.0001$

a limited number of elective interventions for oncological diseases. The laparoscopic approach was used in $69.6 \%$ of cases on COVID-19 patients. The number of urgent interventions significantly dropped after the introduction of mobility restricting measures by the government (Table 3). Approximately $40 \%$ of surgeons reported an unusual delay in the presentation of nontraumatic abdominal emergencies. In all these cases, fever had been present for several days before hospital admission. Delay was partially related to patient choice, preferring to stay at home until worsening of the symptoms, and partially due to the waiting list for the COVID-19 test at the emergency room. Only 7\% of surgeons reported the occurrence of unexpected complications in COVID-19 patients, with special reference to septic and respiratory complications (Table 4).

While in $100 \%$ of cases, epidemic spread containing measures was put in place for hospital visitors and patients, and adequate strategies to protect health care workers against infection were suboptimal with respect to the WHO recommendations in $70.4 \%$ of hospitals [5].
In addition, nasopharyngeal swabs (NS) were performed on symptomatic surgeons only and were not performed at all in $77.5 \%$ and $12.7 \%$, respectively, of hospitals. Similarly, NS were performed only on symptomatic patients and none of the surgical patients in $67.6 \%$ and $16.9 \%$, respectively, of hospitals. Finally, advanced personal protective equipment (PPE) for operating room workers was adopted for all interventions in only $12.7 \%$ of hospitals and measures to reduce the dispersion of biological aerosol during minimally invasive operations were adopted in only $35.2 \%$ of the operating rooms (Table 5).

\section{Discussion}

While international scientific societies are rapidly producing recommendations dealing with COVID-19 outbreak [4-8], a starting point is useful in order to frame the operating areas that deviate most from the recommendations, on which it will be necessary to insist more. We performed the current inquiry during the peak of the COVID-19 outbreak in Italy (March 26-28, 2020), giving a very short answering time $(48 \mathrm{~h})$ in order to gather a

Table 4 Emergency surgery in COVID-19 + cases

\begin{tabular}{|c|c|c|c|}
\hline & & Number & Percent \\
\hline \multirow[t]{2}{*}{ Surgical interventions in COVID-19+ } & No & 48 & 67.6 \\
\hline & Yes & 23 & 32.4 \\
\hline \multirow[t]{4}{*}{ Indications to surgery ${ }^{1}$} & Very urgent diseases ${ }^{2}$ & 16 & 22.5 \\
\hline & Urgent diseases $^{3}$ & 11 & 15.5 \\
\hline & Trauma & 3 & 4.2 \\
\hline & Elective oncologic surgery & 4 & 5.6 \\
\hline \multirow[t]{3}{*}{ Surgical approach } & Only laparoscopy & 5 & 7.0 \\
\hline & Only open & 8 & 11.3 \\
\hline & Open and laparoscopy & 10 & 14.1 \\
\hline \multirow[t]{3}{*}{ Comparison with the number of February-March 2019 emergency interventions } & Increased & 8 & 11.3 \\
\hline & Reduced & 39 & 54.9 \\
\hline & Stable & 24 & 33.8 \\
\hline \multirow[t]{2}{*}{ Unusual delay in presentation for urgent pathology ${ }^{4}$} & Yes & 28 & 39.4 \\
\hline & No & 43 & 60.6 \\
\hline \multirow[t]{2}{*}{ Increase in post-operative complication rate } & Yes & 5 & 7.1 \\
\hline & No & 66 & 92.9 \\
\hline
\end{tabular}

${ }^{1}$ In each center, more than 1 answer was reported

${ }^{2}$ For example, bowel perforations, diffuse peritonitis, and septic shock, hemorrhages with shock, bowel ischemia, and necrosis

${ }^{3}$ For example, acute appendicitis with localized peritonitis, acute cholecystitis, and obstruction

${ }^{4}$ For example, unusual high rate of acute gangrenous appendicitis, perforated cholecystitis, and stanched bowel perforation 
Table 5 PPE supply and utilization

\begin{tabular}{|c|c|c|c|}
\hline & & Number & Percent \\
\hline \multirow[t]{2}{*}{ Institutional measures for visitors } & Yes & 71 & 100 \\
\hline & No & 0 & 0 \\
\hline \multirow[t]{2}{*}{ Institutional measures for patients } & Yes & 71 & 100 \\
\hline & No & 0 & 0 \\
\hline \multirow[t]{2}{*}{ Institutional measures for surgeons } & Yes & 50 & 70.4 \\
\hline & No & 21 & 29.6 \\
\hline \multirow[t]{3}{*}{ Swabs on operated patients } & Yes, all operated patients & 11 & 15.5 \\
\hline & Nobody & 12 & 16.9 \\
\hline & Only for symptomatic & 48 & 67.6 \\
\hline \multirow[t]{3}{*}{ Swabs on surgeons } & Yes, all surgeons & 7 & 9.8 \\
\hline & Nobody & 9 & 12.7 \\
\hline & Only for symptomatic & 55 & 77.5 \\
\hline \multirow[t]{3}{*}{ Advanced PPE for professionals in OR during surgery } & Yes, all cases & 9 & 12.7 \\
\hline & Never & 22 & 30.9 \\
\hline & Only for documented COVID+ pts & 40 & 56.3 \\
\hline \multirow[t]{3}{*}{ Measures to reduce the dispersion of biological aerosol during MIS } & Yes & 25 & 35.2 \\
\hline & No & 46 & 64.8 \\
\hline & Only for documented COVID+ pts & 0 & 0 \\
\hline
\end{tabular}

MIS minimally invasive surgery

true "snapshot" of the situation. Although the overall compliance rate (43.7\%) was low, it nonetheless represents a good sample of Italian general surgery units.

First, the COVID-19 pandemic has an enormous impact on surgery: over $80 \%$ of surgical departments changed their practices, $70 \%$ shifted work plans, and in 1 out of 2 of them, some team members were allocated to non-surgical departments. About 1 out of 3 surgical departments had team members who were sick or in preventive quarantine. This confirms that the pandemic extensively affects the surgical activities, as already stated [12]. It is therefore strongly advisable that international scientific societies develop unequivocal recommendations which do not contrast with each other.

Focusing on urgent interventions, about half of the centers reported a drop in the overall number of urgent cases (Table 3), however, associated with a more severe presentation due to a diagnostic delay. Many patients with fever are asked by the authorities not to go to the hospital if they do not have breathing difficulties. In these patients, the fever may not be caused by COVID19-related pneumonia but by an abdominal infection. There are also a number of patients whose diagnostic delay is linked to the time spent in the emergency room, both because of the scarcity of available hospital beds and because of the diagnostic work-up for COVID-19. Thus, it may be useful that recommendation statements devote attention also to the pre-hospital phase and to the management of patients in the emergency room.
The surgical attitude does not seem to have changed significantly in COVID-19 patients, with particular reference to the use of the laparoscopic approach. Indeed, over 2 out of 3 patients were operated on with a minimally invasive technique. The submitted questionnaire does not allow a detailed analysis of post-operative results. However, only $7 \%$ of surgeons reported unexpected post-operative complications. Pulmonary complications and unexpected fever were the most common complications reported in positive-tested COVID-19 patients who undergone surgery irrespectively to the type of surgery and surgical approach. This is in partial contrast to recent observations, nevertheless reporting on a very small number of cases [13]. It seems important that recommendations generated by the international scientific societies take into account the observation of Italian general surgeons that the laparoscopic approach does not significantly worsen the outcomes. Recommendations against the use of laparoscopy seem to be linked more to theoretical and physio-pathological considerations than to real data. It is likely that these recommendations, conflicting with the personal opinion of most surgeons, will be little applied in daily practice, generating a significant amount of malpractice claims.

With regard to PPE supply and utilization, there is a significant gap between official recommendations [1417] and daily clinical practice. In more than 1 out of 4 hospitals, no measures to reduce the health workers' infections are reported. In almost all centers, NS are 
performed only on symptomatic surgeons and only on symptomatic surgical patients. In less than 1 out of 10 and 1 out of 6 cases, NS are performed on all surgeons and all surgical patients, respectively. Finally, intraoperative recommendations $[18,19]$ are very rarely respected in our survey. Recommendations on this issue must be based on incontrovertible data and not on theoretical considerations; otherwise, a large number of legal complaints will be promoted by health professionals against the hospitals.

\section{Conclusions}

Two main considerations arise from the data of this survey. Contraction of admissions for urgent and emergent conditions in the first period of lockdown could be followed by a rebound surge of a large amount of patients with complicated acute diseases quickly overloading responsiveness of the few human resources and the already crowded intensive care units and surgical wards. In Italy, a few number of centers are in condition to adopt the scientific society guidelines to support patient and health care workers' safety. Both situations require new strategies to improve the health system response to the emergency into an emergency that is reasonably here to come [20]. The at-home patient care model should be implemented in order to identify patients requiring emergency surgery. General practitioners should be appointed to select patients before referral to ED and be furnished of all the PPE that are still scarce for general practice. Physical examination and basic diagnostic procedures (abdominal, chest ultrasound, and NS) settled at home are of paramount importance for patient selection before access to the ED where, to date, time for diagnostic and therapeutic procedures is prolonged waiting for the results of NS. Efforts to maintain in the ED separate COVID-free pathways that guarantee basic assistance for urgent diseases are another element to speed up the treatment of emergency cases and mitigate the patients' fear of being infected in the hospital.

\section{Abbreviations}

ED: Emergency department; ICU: Intensive care unit; MIS: Minimally invasive surgery; NS: Nasopharyngeal swabs; PPE: Personal protective equipment; WHO: World Health Organization

\section{Acknowledgements}

We want to acknowledge the fellows of the Associazione Chirurghi Ospedalieri Italiani who answered to the questionnaire. We would like the names of the individual members of the Group to be searchable through their individual PubMed records:

Di Venere Beatrice, Sallustio Pierluca Nicola Massimo, Siquini Walter, Sorrentino Mario, Polastri Roberto, Armellino Mariano Fortunato, Scatizzi Marco, Giuliani Antonio, Maggioni Dario, Rizzi Andrea, Bonilauri Stefano, Cimino Giuseppe, Contine Alessandro, Borghi Felice, Parisi Amilcare, Longo Graziano, De Luca Stefano, Testa Silvio, Elio Amedeo, Bellochi Raffaele, Boncompagni Michela, Delogu Leonardo Andrea, Gattolin Andrea, Santi Stefano, Agresta Ferdinando, Bottino vincenzo, Ubiali Paolo, Scuderi Vincenzo, Verzelli Augusto, Cicetti Moreno, Clementi Marco, Annesi Matteo, Stracqualursi Antonio, Sarro Giuliano, Coletta Pietro, Spaziani Alessandro,
Pernazza Graziano, Castaldo Pasquale, Spampinato Marcello Giuseppe, Bartoli Alberto, Tirrò Antonino, Cocozza Eugenio, Ferrero Alessandro, Berti Stefano, Perrotta Michele, De Manzini Nicolò, Castagnoli Giampaolo, Celi Daniele, Taglietti Lucio, Vettoretto Nereo, Rabuini Claudio, Santarelli Mauro, Kiss Alberto, Vicentini Roberto, Risio Domenico, Bazzi Piero, Cillara Nicola, Cuticone Giuseppe, Miconi Guglielmo, Cesari Maurizio, Ciaccio Giovanni, larrobino Gianfausto, Gambardella Denise, Ceccarelli Graziano, Bordoni Pierpaolo, Isolani Simone Mario.

\section{Authors' contributions}

$A P, G L B, F C, P M$, and $M C$ contributed to the manuscript conception and draft of the manuscript, critically revised the manuscript, contributed with important scientific knowledge, and gave the final approval. The authors read and approved the final manuscript.

Funding

None.

Availability of data and materials

Not applicable.

Ethics approval and consent to participate

Not applicable.

\section{Consent for publication}

Not applicable.

\section{Competing interests}

The authors declare that they have no competing interests.

\section{Author details}

${ }^{1}$ Department of Surgery, Azienda Ospedaliera Marche Nord, Ospedale San Salvatore, Piazzale Cinelli 1, Pesaro-Fano, Italy. ${ }^{2}$ Department of Clinical and Experimental Sciences, University of Brescia, Brescia, Italy. ${ }^{3}$ Emergency Surgery Unit, AOU Parma, Parma, Italy. ${ }^{4}$ General Surgery Unit, Azienda Ospedaliera San Camillo-Forlanini, Roma, Italy. ${ }^{5}$ General Surgery Unit, Ospedale "C. e G. Mazzoni", ASUR Marche AV5, Ascoli Piceno, Italy.

Received: 6 April 2020 Accepted: 6 May 2020

Published online: 24 May 2020

\section{References}

1. Centers for Disease Control and Prevention. Coronavirus disease 2019 (COVID-19) situation summary. Available from URL: https://www.cdc.gov/ coronavirus/2019-ncov/summary.html (accessed March 2020).

2. Zhu N, Zhang D, Wang W, Li X, Yang B, Song J, Zhao X, Huang B, Shi W, Lu R, Niu P, Zhan F, Ma X, Wang D, Xu W, Wu G, Gao GF, Tan W. China novel coronavirus investigating and research team. N Engl J Med. 2020 Feb 20; 382(8):727-33.

3. Remuzzi A, Remuzzi G. COVID-19 and Italy: what next? Lancet. 2020. https:// doi.org/10.1016/S0140-6736(20)30627-9. Epub ahead of print.

4. Intercollegiate General Surgery Guidance on COVID-19 UPDATE. https:// www.rcsed.ac.uk/news-public-affairs/news/2020/march/intercollegiategeneral-surgery-guidance-on-covid-19-update.

5. Tao KX, Zhang BX, Zhang P, Zhu P, Wang GB, Chen XP; General Surgery Branch of Hubei Medical Association, General Surgery Branch of Wuhan Medical Association. Recommendations for general surgery clinical practice in 2019 coronavirus disease situation. Zhonghua Wai Ke Za Zhi. 2020;58(3): 170-7. https://doi.org/10.3760/cma.j.issn.0529-5815.2020.03.003. Chinese.

6. American College of Surgeons releases recommendations for surgical management of elective operations during COVID-19 pandemic. https:// www.facs.org/about-acs/covid-19/information-for-surgeons.

7. Maintaining trauma center access and care during the COVID-19 pandemic: guidance document for trauma medical directors. Online March 20, 2020. https://www.facs.org/covid-19/clinical-guidance/maintaining-access.

8. SAGES and EAES recommendations regarding surgical response to COVID19 crisis. Released 3/30/2020. https://www.sages.org/recommendationssurgical-response-covid-19/.

9. Zheng $\mathrm{MH}$, Boni L, Fingerhut $\mathrm{A}$. Minimally invasive surgery and the novel coronavirus outbreak: lessons learned from Italy. Ann Surg. 2020. 
10. Spinelli A, Pellino G. COVID-19 pandemic: perspectives on an unfolding crisis. Br J Surg. 2020. https://doi.org/10.1002/bjs.11627.

11. Catena F, Biffl W, De Simone B, Sartelli M, Di Saverio S, Kluger Y, Moore EE, Ansaloni L, Coccolini F. Emergency general surgeons: the special forces of general surgery (the "navy seals paradigm"). World J Emerg Surg. 2020 Feb 12;15(1):11. https://doi.org/10.1186/s13017-020-0293-7.

12. Brindle M, Gawande A. Managing COVID-19 in surgical systems. Ann Surg. 2020. https://doi.org/10.1097/SLA.0000000000003923. Epub ahead of print. No abstract available.

13. Aminian A, Safari S, Razeghian-Jahromi A, Ghorbani M, Delaney CP. COVID19 outbreak and surgical practice: unexpected fatality in perioperative period. Ann Surg. 2020. https://doi.org/10.1097/SLA.0000000000003925.

14. Infection prevention and control during health care when COVID-19 is suspected. Interim guidance 19 March 2020. https://www.who.int/ publications-detail/infection-prevention-and-control-during-healthcarewhen-novel-coronavirus-(ncov)-infection-is-suspected-20200125.

15. NHS. Clinical guide for the management of non-coronavirus patients requiring acute treatment: cancer. 23 March 2020 Version 2. https://www. england.nhs.uk/coronavirus/publication/specialty-guides/.

16. Lee IK, Wang $C C$, Lin MC, Kung $C T$, Lan $K C$, Lee $C T$. Effective strategies to prevent coronavirus disease-2019 (COVID-19) outbreak in hospital. J Hosp Infect. 2020. https://doi.org/10.1016/j.jhin.2020.02.022

17. The Lancet. COVID-19: protecting health-care workers. Lancet. 2020 Mar 21; 395(10228):922. https://doi.org/10.1016/S0140-6736(20)30644-9.

18. Wong J, Goh QY, Tan Z, Lie SA, Tay YC, Ng SY, Soh CR. Preparing for a COVID-19 pandemic: a review of operating room outbreak response measures in a large tertiary hospital in Singapore. Can J Anaesth. 2020;11.

19. Ti LK, Ang LS, Foong TW. Ng BSW What we do when a COVID-19 patient needs an operation: operating room preparation and guidance. Can J Anaesth. 2020;6.

20. Patriti A, Eugeni E, Guerra F. What happened to surgical emergencies in the era of COVID-19 outbreak? Considerations of surgeons working in an Italian COVID-19 red zone.Updates Surg. 2020. https://doi.org/10.1007/s13304-02000779-6. Ahead of print.

\section{Publisher's Note}

Springer Nature remains neutral with regard to jurisdictional claims in published maps and institutional affiliations.

Ready to submit your research? Choose BMC and benefit from:

- fast, convenient online submission

- thorough peer review by experienced researchers in your field

- rapid publication on acceptance

- support for research data, including large and complex data types

- gold Open Access which fosters wider collaboration and increased citations

- maximum visibility for your research: over $100 \mathrm{M}$ website views per year

At $\mathrm{BMC}$, research is always in progress.

Learn more biomedcentral.com/submissions 